\title{
Development of a microinjection system for RNA interference in the water flea Daphnia pulex
}

\author{
Chizue Hiruta', Kenji Toyota1,2, Hitoshi Miyakawa', Yukiko Ogino ${ }^{1,2}$, Shinichi Miyagawa ${ }^{1,2}$, Norihisa Tatarazako ${ }^{3}$, \\ Joseph R Shaw ${ }^{4}$ and Taisen Iguchi ${ }^{1,2^{*}}$
}

\begin{abstract}
Background: The ubiquitous, freshwater microcrustacean Daphnia pulex provides a model system for both human health research and monitoring ecosystem integrity. It is the first crustacean to have a well annotated, reference genome assembly that revealed an unusually high gene count highlighted by a large gene orphanage,-i.e., previously uncharacterized genes. Daphnia are capable of either clonal or sexual reproduction, making them ideally suited for genetic manipulation, but the establishment of gene manipulation techniques is needed to accurately define gene functions. Although previous investigations developed an RNA interference (RNAi) system for one congener $D$. magna, these methods are not appropriate for $D$. pulex because of the smaller size of their early embryos. In these studies, we develop RNAi techniques for $D$. pulex by first determining the optimum culture conditions of their isolated embryos and then applying these conditions to the development of microinjection techniques and proof-of-principle RNAi experiments.

Results: We found that isolated embryos were best cultured on a $2 \%$ agar plate bathed in $60 \mathrm{mM}$ sucrose dissolved in M4 media, providing optimal conditions for microinjections. Then, we injected double-stranded (ds) RNA specific to the Distal-less gene (D/l), which is a homeobox transcription factor essential for limb development in invertebrates and vertebrates. Injected embryos presented with defects in the second antenna and appendage development, and dsRNA induced the degradation of DII mRNAs, indicating that this technique successfully inhibited transcription of the target gene.
\end{abstract}

Conclusions: We developed a microinjection system for RNAi studies in D. pulex. These techniques add to the growing genomic toolbox and enhance the genetic tractability of this important model for environmental, evolutionary, and developmental genomics.

Keywords: Daphnia pulex, Microinjection, RNA interference, Distal-less, Parthenogenetic egg

\section{Background}

In both basic and human health research, there is a pressing need to understand how environmental conditions influence gene functions and, in turn, how individuals and populations cope with changing environments. Invertebrate species have emerged as models for experimental manipulation because of their unique biological attributes, life cycles, large numbers of offspring, easy

\footnotetext{
*Correspondence: taisen@nibb.ac.jp

'Okazaki Institute for Integrative Bioscience, National Institute for Basic Biology, National Institutes of Natural Sciences, 5-1 Higashiyama, Myodaiji, Okazaki, Aichi 444-8787, Japan

${ }^{2}$ Department of Basic Biology, Faculty of Life Science, Graduate University for Advanced Studies (SOKENDAl), 5-1 Higashiyama, Myodaiji, Okazaki, Aichi 444-8787, Japan

Full list of author information is available at the end of the article
}

maintenance, and sophisticated tools for high-throughput biology and open-source informatics [1]. However, the traits observed in laboratories are likely a small subset of the phenotypic variation that is expressed in natural ecosystems. This may partly explain why 15 to $50 \%$ or more genes are without experimentally determined functional annotations, even within the best-characterized genomes (e.g., yeast; [2]).

Daphnia possess several characteristics that make them valuable for environmental, evolutionary, and developmental genomics research-addressing the added complexity of genome-environment interactions. Daphnia are a ubiquitous, and ecologically important member of freshwater lakes and ponds, and have long been used as a sentinel of the integrity of these aquatic ecosystems. More recently 
with the release of the $D$. pulex genome [3], it now serves as a recognized surrogate model for human health research. The $D$. pulex genome possesses more genes than any previously sequenced animal genome $(\sim 31,000)$, due to a large orphanage of Daphnia genes that likely, allows the organism to respond to its environment [3]. In addition to their short generation time, large brood sizes, and ease of laboratory and field manipulation, Daphnia are capable of either clonal or sexual reproduction, making them ideally suited for genetic studies. At present, however, there are no effective methods for manipulating genes and characterizing gene function, which because of the large gene orphanage limits interspecies extrapolations.

RNA interference (RNAi) is an evolutionarily conserved post-transcriptional gene silencing mechanism, which is triggered by double-stranded (ds)RNA in a sequence specific manner [4,5]. Since RNAi was first reported in the nematode Caenorhabditis elegans by Fire et al. [6], it has been used as a powerful tool for the analysis of gene function in many organisms such as zebrafish Danio rerio [7], planarian Schmidtea meditteranea [8], cnidarian Hydra magnipapillata [9], fungus Neurospora crassa [10], fruit-fly Drosophila melanogaster [11] and mouse Mus musculus [12]. Microinjection is one method of introducing dsRNA into cells, and this method has been successfully developed for the daphnid species, D. magna [13]. In fact, microinjection techniques enabled the application of not only RNAi $[13,14]$, but also overexpression of foreign genes [15] and the creation of transgenic individuals [16]. Establishing these techniques in $D$. pulex will extend the resources for environmental, evolutionary, and developmental genomics research for this species by providing needed tools to characterize gene function.

Distal-less $(D l l)$ and its homologs $D l x$ genes, which function as homeodomain transcription factors, play one of the major roles in limb development throughout the animal kingdom [17]. Reduction of $D l l$ activity caused defects of distal leg segments in arthropods including insects [18-20], crustaceans (Parhyale hawaiensis [21],
D. magna [13]), the spider Cupiennius salei [22] and the spider mite Tetranychus urticae [23]. Because of its conserved role in limb development, defects in the expression of the $D l l$ gene produce easily recognizable phenotype and ease of evaluation of its phenotype, which is why this endogenous developmental gene was selected as a target in proof-of-principle RNAi in D. pulex.

The goal of this study was to develop a microinjection system for RNAi in D. pulex. Culture requirements for isolated embryos were first determined and then microinjection techniques developed for conducting RNAi experiments using Dll-dsRNA.

\section{Results and discussion}

\section{Development of microinjection system}

There are two major technical problems for microinjection in daphnid species. One is the rapid hardening of egg membrane [24] and the other is a considerable difference between the internal and external osmotic pressures of the egg. The former prevents egg membrane penetration by a needle, and the latter produces leaking of internal contents (yolk, oil droplets, and so on) when the needle is withdrawn. Kato et al. [13] determined the proper condition for microinjection in $D$. magna. Eggs were incubated on ice just after ovulation to inhibit the membrane hardening transiently and placed in plastic petri dish with $80 \mathrm{mM}$ sucrose medium dissolved by M4 culture medium (M4) to increase external osmotic pressure. However, these conditions are not suitable for $D$. pulex possibly because of the difference in egg size and form (Additional file 1). To overcome these hurdles, we first examined culture conditions by varying sucrose concentration and culture media, and determining those conditions that allowed embryos isolated from the brood chamber to develop normally. Survival was greater in M4 culture media as compared to dechlorinated freshwater (FW) (Table 1). A sucrose concentration of $40 \mathrm{mM}$ on a $2 \%$ agar plate yielded the greatest viability, but this concentration of sucrose was not high enough to counter the internal osmolality and,

Table 1 The relationship between culture conditions and viability (survived juveniles/ total eggs)

\begin{tabular}{|c|c|c|c|c|c|}
\hline & $160 \mathrm{mM}(\mathrm{FW})$ & $80 \mathrm{mM}$ (FW) & $60 \mathrm{mM}(\mathrm{FW})$ & 40 mM (FW) & $0 \mathrm{mM}(\mathrm{FW})$ \\
\hline Glass petri dish & $0 \%(0 / 34)$ & $13.9 \%(5 / 36)$ & $45.9 \%(17 / 37)$ & $54.1 \%(20 / 37)$ & $69.6 \%(48 / 69)$ \\
\hline Plastic petri dish & $0 \%(0 / 56)$ & $8.5 \%(5 / 59)$ & $48.6 \%(35 / 72)$ & $59.5 \%(25 / 42)$ & $64.8 \%(35 / 54)$ \\
\hline \multirow[t]{2}{*}{$2 \%$ agar plate } & $0 \%(0 / 40)$ & $17.9 \%(7 / 39)$ & $72.5 \%(29 / 40)$ & $65.3 \%(32 / 49)$ & $79.2 \%(38 / 48)$ \\
\hline & & & $60 \mathrm{mM}(\mathrm{M} 4)$ & 40 mM (M4) & $0 \mathrm{mM}$ (M4) \\
\hline Glass petri dish & & & $61.9 \%(26 / 42)$ & $77.1 \%(27 / 35)$ & $88.5 \%(31 / 35)$ \\
\hline Plastic petri dish & & & $62.7 \%(32 / 51)$ & $70.0 \%(28 / 40)$ & $86.8 \%(33 / 38)$ \\
\hline $2 \%$ agar plate & & & $88.9 \%(40 / 45)$ & $90.9 \%(40 / 44)$ & $96.4 \%(53 / 55)$ \\
\hline
\end{tabular}

Left column represents types of culture plate and top row shows sucrose concentration of culture medium. Sucrose was dissolved in freshwater (FW) or M4 culture medium (M4). 
therefore, not sufficient for injection (Table 1). Taken together, a $2 \%$ agar plate covered with $60 \mathrm{mM}$ sucrose dissolved in M4 media provided the best conditions for microinjection of $D$. pulex early embryos, and was employed in subsequent experiments. These conditions allowed embryos to be injected within 30 to $60 \mathrm{~min}$ of isolation. It is critical that injections occur within the first hour following ovulation, because there is no cytokinesis during this period and dsRNA can easily diffuse throughout the egg as it remains a single cell [25].

\section{RNAi using microinjection in D. pulex}

The dsRNA was prepared from a 500 bp region derived from the $D l l$ gene (Dll-dsRNA; Additional file 2), and dsRNA derived from a 729-bp region of the Escherichia coli malE gene (malE-dsRNA) was developed as a negative control. There is only one $D l l$ gene in the $D$. pulex genome (gene ID: NCBI_GNO_194714, scaffold_121: 199759-203057). The Dll-dsRNA was synthesized from a region that included the homeodomain. Red fluorescence was used to judge whether microinjection were successful (Figure 1). Results from RNAi experiments are summarized in Table 2 . Only $57 \%$ of the embryos injected with Dll-dsRNA developed compared to $71.1 \%$ viability of those injected with of malE-dsRNA, indicating $D l l$-dsRNA produced embryonic lethal phenotypes. Embryonic lethality caused by loss of DLL functions was reported in insects $[19,26]$.

\section{Sequence-specific gene silencing of $D$. pulex DII}

We injected $1 \mu \mathrm{g} / \mu \mathrm{l}$ dsRNA with a fluorescent dye into each egg and measured the endogenous Dll mRNA levels using Q-PCR at $24 \mathrm{~h}$ after injection to determine if $D l l$-dsRNA triggers the degradation of endogenous $D l l$ mRNAs. The quantity of Dll mRNA in Dll-dsRNA-

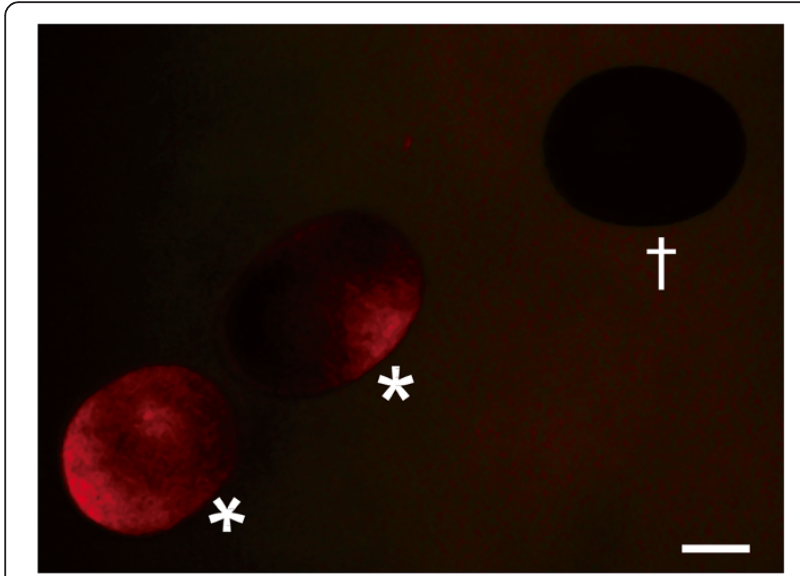

Figure 1 dsRNA-injected $(*)$ and uninjected $(t)$ eggs. Asterisks indicate parthenogenetic eggs just after microinjection of dsRNA with a red fluorescent Chromeo494 dye. Scale bar $=100 \mu \mathrm{m}$.
Table 2 Summary of RNAi using dsRNA

\begin{tabular}{cccccc}
\hline dsRNA & $\begin{array}{c}\text { Injected } \\
\text { eggs }\end{array}$ & Juveniles & $\begin{array}{c}\text { Viability } \\
\text { (\%) }\end{array}$ & $\begin{array}{c}\text { Shortened } \\
\text { 2nd antennae }\end{array}$ & $\begin{array}{c}\text { Ocellus } \\
\text { deletion }\end{array}$ \\
\hline DII & 90 & 51 & 57 & 51 & 34 \\
malE & 59 & 42 & 71.1 & 0 & 0 \\
\hline
\end{tabular}

injected embryos was decreased to $43.9 \%( \pm 9.4 \%)$ of that in malE-dsRNA-injected control embryos (Figure 2). These results were generally consistent with the result of D. magna where a $43.6 \%( \pm 2.5 \%)$ reduction in $D l l$ was observed [13].

\section{Phenotype of DII RNAi in D. pulex}

We confirmed the spatial expression pattern of $D l l$ in embryo using whole-mount in situ hybridization. Dll was strongly expressed in the distal portion of second antenna, appendages (from the first to fifth thoracic limbs) and labrum, and weakly expressed in first antenna, mandible and first maxilla between 25 to $30 \mathrm{~h}$ post ovulation (Figure 3). Dll-dsRNAi injection of isolated embryos produced defects in the Dll-expressing organs (second antennae, appendages, ocellus, abdominal claw, and abdominal setae) to various degrees. These defects included a truncation of the second antenna segments (Figure 4) that resembled a phenotype observed in D. magna Dll-RNAi experiments [13]. The first to fifth thoracic appendages, including each exopodite, were shortened (Figure 4 and Additional file 3). In arthropods truncation of the distal portion of the appendages is one of the well-known phenotypes observed in $\mathrm{Dll}$ mutation/knockdown [13,18-23]. In addition, a loss of the ocellus and abdominal setae, and a minimized abdominal claw (Additional file 3) were observed in DlldsRNA injected embryos, which are also concordant with D. magna [13]. Although expression of $D l l$ in the ocellus

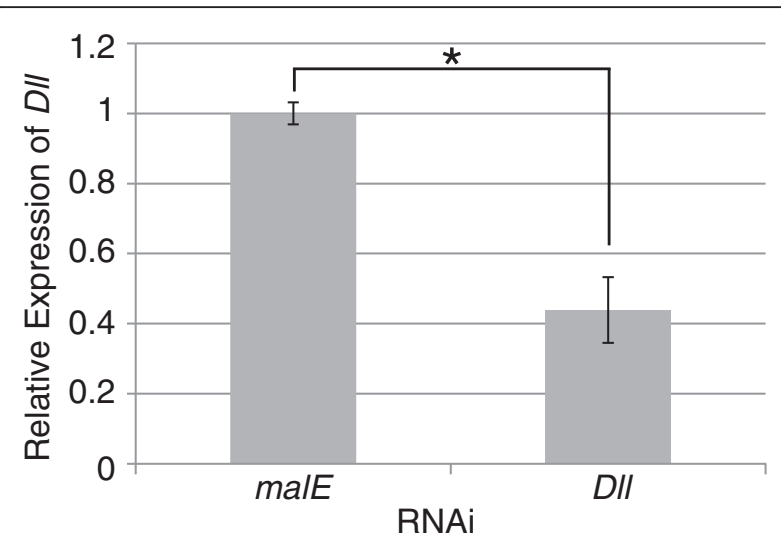

Figure 2 DIl expression level in embryos injected with dsRNA of malE and DII. The error bar indicates a mean value \pm standard error calculated from triplicate samples. ${ }^{*}$, value significantly different between malE -dsRNA and DII-dsRNA ( $P<0.01 ; t$-test). 


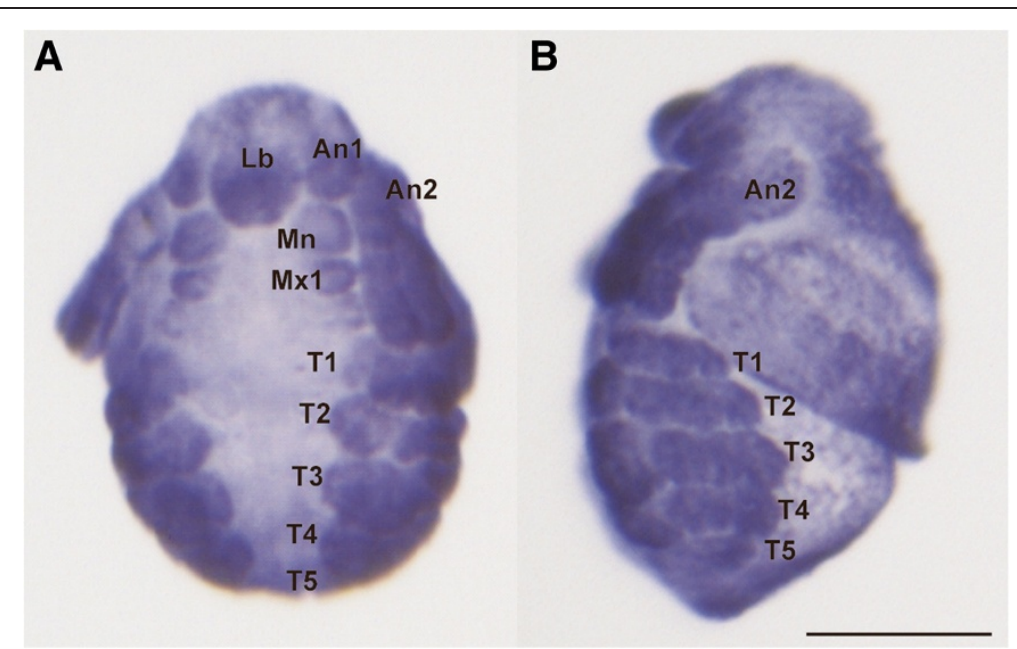

Figure 3 Spatial expression pattern of DII. A. Frontal view. B. Lateral view. Embryos (around 25-30 h after ovulation) show strong D/l signals in first to fifth thoracic limbs, distal portion of second antenna, and labrum, and weak D/l signals in first antenna, mandible and first maxillae. An 1 , first antenna; An2, second antenna; Lb, labrum; Mn, mandible; Mx1, first maxilla; T1-T5, first to fifth thoracic limb. Scale bar = 100 $\mu m$.

has not been reported in any organisms, DLL expression was observed in the prospective ocellus region of $D$. magna [27]. The injection of non-D. pulex malE-dsRNA did not induce any morphological abnormalities in $D$. pulex embryos (Figure 3, Additional file 3, and Table 2). These data strongly suggest that the observed phenotypes were specifically generated by $D l l$-dsRNA, mediating the disruption of endogenous $D l l$ mRNAs, in D. pulex.

\section{Conclusions}

We developed a microinjection system for RNAi in $D$. pulex. The optimum conditions for microinjection were a 2\% agar plate with $60 \mathrm{mM}$ sucrose dissolved in M4 media. RNAi can be induced in early embryos by injecting dsRNA into eggs within 1 hour post-ovulation. The microinjection system is applicable to not only RNAi but also creation of transgenic animals, labeling specific target cells, and so on. Thus this technique will contribute $D$. pulex to become a more appropriate species as model organism for environmental, evolutionary, and developmental biology.

\section{Methods}

\section{Daphnia strains and culture conditions}

The D. pulex were obtained from the Center for Genomics and Bioinformatics (Indiana University, USA) and the National Institute for Environmental Studies (Tsukuba, Ibaraki, Japan). The strains were maintained in dechlorinated freshwater (FW), which was aerated and filtered through activated carbon for 2 weeks, at $18^{\circ} \mathrm{C}$ under artificial light conditions of $14 \mathrm{~h}$ light and $10 \mathrm{~h}$ dark to maintain reproduction. A $0.01-\mathrm{ml}$ suspension of $10^{9}$ cells/ml Chlorella vulgaris was added every day to each culture (20-25 individuals/L). For rearing embryos,
M4 culture medium (M4) was prepared using MilliQ water [28].

\section{Culture requirements for isolated eggs}

Culture conditions were evaluated to determine the optimum conditions for microinjection. Eggs were dissected from brood chamber just after ovulation using forceps (Dumoxel \#5 Biologie, Dumont, Montignez, Switzerland) and placed in a culture plate (glass petri dish, plastic petri dish) containing $2 \%$ agar and sucrose $(160,80,60,40 \mathrm{mM})$. Sucrose was dissolved in either FW or M4, as described in the Results and Discussion. These media were passed through a $0.45 \mu \mathrm{m}$ filter (\#431220; Corning, Steuben County, NY, USA) before use. Embryo viability (survived juveniles/total eggs) was evaluated during the first instar juvenile stage.

\section{Cloning of Distal-less}

Total RNA was extracted using an ISOGEN kit (NIPPON GENE, Tokyo, Japan), and converted to cDNA using Superscript III and random primers (Life Technologies, Carlsbad, CA, USA) according to the manufacturer's protocol. The Dll fragment was PCR amplified from the cDNA using a set of primers designed from the Dll sequence retrieved from wFleaBase http://wfleabase. org/ (Additional file 4). Subsequently, the cDNA fragments were cloned into the pGEM-T vector (Promega, Madison, WI, USA) according to the manufacturer's instructions. These were sequenced using Sanger techniques that included the Big Dye terminator kit on an ABI 3100 Avant DNA sequencer (Applied Biosystems Japan Ltd, Tokyo, Japan). Two separate clones were developed with same $D l l$ region oriented in both directions for dsRNA preparation. 


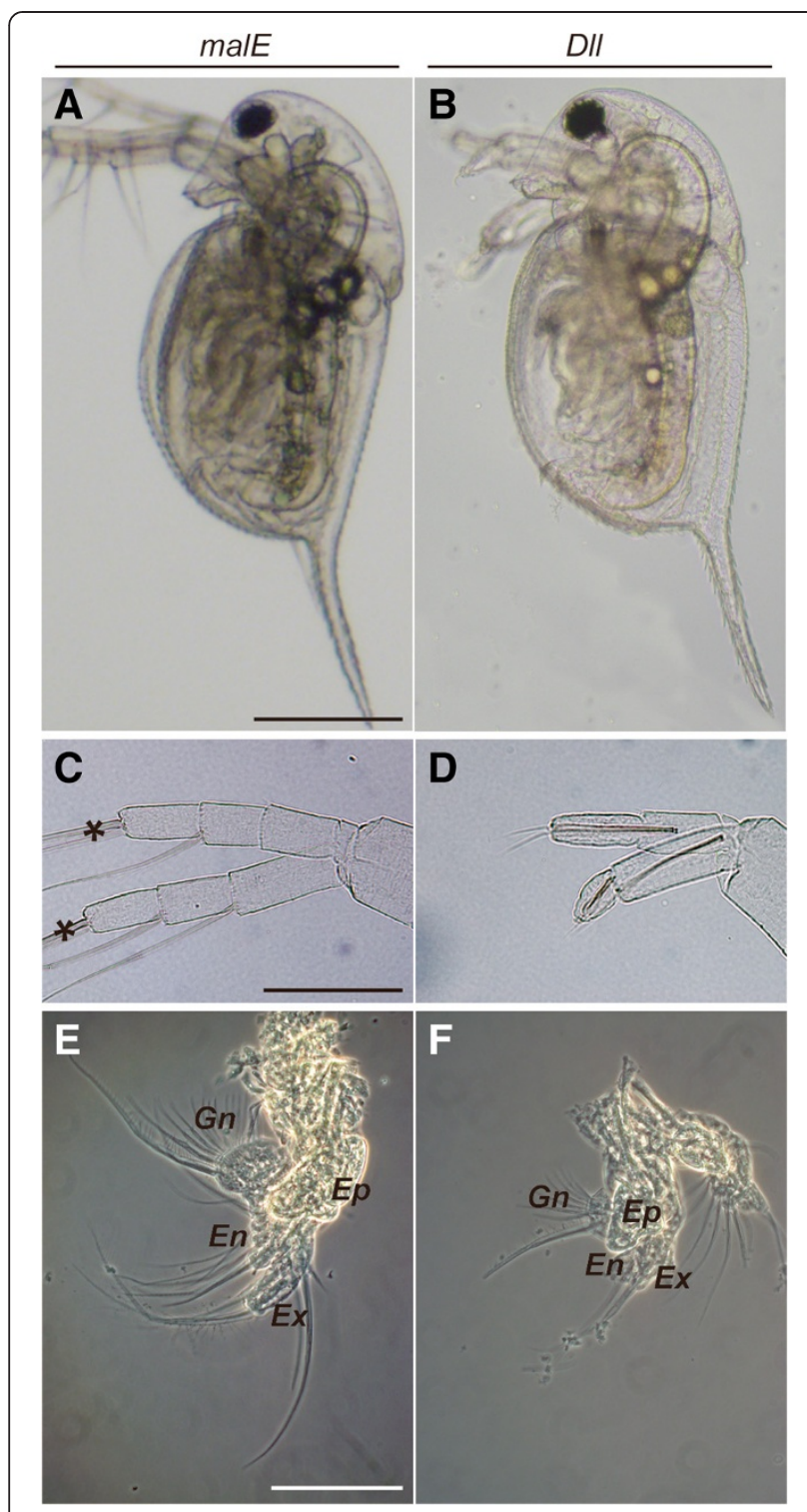

Figure 4 Major DII-RNAi phenotypes. The left and right columns show phenotypes of individuals injected with dsRNA of malE and DII, respectively. (A, B) Lateral view of first instar juvenile. (C, D) Lateral view of second antennae. Asterisks indicate the distal portions of the second antennae. (E, F) Second thoracic limb (T2). Ep, epipodite; En, endopodite; Ex, exopodite; Gn, gnathobase. Scale bars $=200 \mu \mathrm{m}$ in $\mathbf{A}, \mathbf{B} ; 100 \mu \mathrm{m}$ in $\mathbf{C}, \mathbf{D}$ and $\mathbf{E}, \mathbf{F}$.

\section{Whole-mount in situ hybridization}

Dll transcripts were visualized by whole-mount in situ hybridization with a $D l l$ antisense RNA probe. The 522 bp probes were synthesized using a set of primers (Additional file 4). Embryos at 25-30 h after oviposition were dissected from brood chamber. The samples were transferred into a 1:4 mixture of $4 \%$ paraformaldehyde in PBS and heptane for $20 \mathrm{~min}$ and rinsed 5 times in PBT (0.1\% Tween 20 in PBS). These embryos were digested with proteinase $\mathrm{K}(4 \mathrm{mg} / \mathrm{ml})$ for $15 \mathrm{~min}$ and then rinsed 2 times in PBT. After post-fixation in $4 \%$ paraformaldehyde for $20 \mathrm{~min}$, the embryos were rinsed 5 times in PBT and once in a 1:1 mixture of hybridization buffer (HB) and PBST, then transferred to $\mathrm{HB}$ at $65^{\circ} \mathrm{C}$ for at least $2 \mathrm{~h}$. The pre-hybridization buffer was replaced with RNA probe in $\mathrm{HB}(5 \mathrm{ng} / \mathrm{mL})$ and incubated overnight at $60^{\circ} \mathrm{C}$. The digoxigenin (DIG)-labeled RNA probe was prepared from the cloned partial sequences using DIG RNA Labeling Mix (Roche, Mannheim, Germany). Embryos were then rinsed in HB (2:1), 1:1 mixtures of HB and PBST, and washed in PBST 5 times. The DIG hapten was detected with a 1:500 dilution of anti-DIG-alkaline phosphatase antibodies (Roche) in PBST for $1 \mathrm{~h}$ at room temperature. The embryo was washed 5 times in PBST and 2 times in the developing solution $[0.1 \mathrm{M} \mathrm{NaCl}, 0.1 \mathrm{M}$ Tris- $\mathrm{HCl}(\mathrm{pH}$ 9.5), $0.05 \mathrm{M}$ $\mathrm{MgCl}_{2}, \quad 0.1 \%$ Tween 20]. The alkaline phosphatase enzyme was detected with NBT/BCIP stock solution (Roche). Embryos were destained in methanol and rehydrated in PBST.

\section{Preparation of double-stranded RNA}

Double-stranded RNA was synthesized using the MEGAscript T7 RNAi Kit (Ambion, Austin, TX, USA). Two templates for the in vitro transcription were prepared by PCR using two separate clones (see Cloning of Distal-less section) with T7 primer and one side genespecific primer in each (Additional file 4). The reaction mixes were incubated for $4 \mathrm{~h}$ at $37^{\circ} \mathrm{C}$, then synthesized sense and antisense RNA were annealed at $75^{\circ} \mathrm{C}$ for $5 \mathrm{~min}$. This was followed by nuclease digestion to remove DNA and single-stranded RNA, and purification of dsRNA was performed according to manufacturer's recommended protocol. malE-dsRNA was prepared according to methods detailed in Kato et al. [13].

\section{Injection of double-stranded RNA}

The molt of female provides a reference time point of parthenogenetic cycle, which proceeds along a strict time course at $18^{\circ} \mathrm{C}$ [25]. The female begins to extrude eggs into the brood chamber at $13 \mathrm{~min}$ after molting. Eggs were obtained just after ovulation by two week old D. pulex and placed in ice-cold M4 medium containing $60 \mathrm{mM}$ sucrose (M4-sucrose). M4-sucrose was passed through a $0.45 \mu \mathrm{m}$ filter (\#431220; Corning) before use. The synthesized dsRNA $(2 \mu \mathrm{g} / \mu \mathrm{l})$ was mixed with an equal amount of $2 \mathrm{mM}$ Chromeo 494 fluorescent dye (Active Motif Chromeon GmbH, Tegernheim, Germany), which was used as a visible marker for injection. A glass needle was made from a glass capillary tube (GD-1; NARISHIGE, Tokyo, Japan) by a Sutter Instrument (Novato, CA, USA), and the tip was manually cut off using a forceps (Dumoxel \#5 Biologie) under a stereomicroscope. A glass petri dish was prepared by placing two cover 
glasses side by side with M4-sucrose. One egg was placed at the left side cover glass edge to immobilize and injected using an injector (Femtojet, Eppendorf, Hauppauge, NY, USA) and a micro-manipulator (M-152, MMO-220A, Narishige, Tokyo, Japan). The needle was withdrawn from the egg using the right side cover glass edge. Microinjections were carried out within $60 \mathrm{~min}$ after ovulation. Then, injected eggs were transferred into a $2 \%$ agar in $6-$ well plate with M4-sucrose and incubated at $18^{\circ} \mathrm{C}$. Firstinstar animals were examined under a stereomicroscope, and their phenotype and viability were recorded.

\section{Quantitative real-time PCR (Q-PCR)}

The relative expression levels of $D l l$ mRNAs associated with the two injected conditions (Dll-dsRNA and malEdsRNA) were quantified and compared using Q-PCR. Thirteen embryos were collected $24 \mathrm{~h}$ following injections with Dll-dsRNA or malE-dsRNA. Total RNA was extracted and purified using RNAqueous-Micro (Ambion) and converted to cDNA with high capacity cDNA reverse transcription kit (Applied Biosystems) using OligodT primers according to the manufacturer's recommended protocol. PCR reactions were performed in an ABI Prism 7000 (Applied Biosystems), using SYBR Green I chemistry (Applied Biosystems) in the presence of appropriate primers. The expression stability and suitability of the eight candidate reference genes (GAPDH, aTub, Tbp, Stx16, Xbp1, MMP, CAPON and Actin) were validated employing geNorm and NormFinder based on Spanier et al. [29]. The actin gene was demonstrated as the most stable reference gene and used for normalization. Primers for both target and control genes were designed to amplify short PCR products of $<150$ bp (Additional file 4). Data acquisition and analysis were performed by ABI Prism 7000 SDS software ver. 1.1 (Applied Biosystems). The Ct (cycle threshold) was set automatically. Samples included three biological replicates were run in triplicate to capture technical variation, and mean and standard errors calculated by Microsoft Excel 2010. Significant differences between the expression levels of Dll and malE-dsRNA injected embryos was determined by the $t$-test.

\section{Additional files}

Additional file 1: Characteristics of egg in $D$. pulex $(A, C)$ and $D$. magna (B, D). Samples were collected just after ovulation. (A, B) Light micrographs. (C, D) Hematoxylin and eosin (HE)-stained cross section. od, oil droplet; yg, yolk granule. Scale bar $=100 \mu \mathrm{m}$.

Additional file 2: Nucleotide sequences of DII-dsRNA.

Additional file 3: Phenotypes of DII-dsRNA injected juveniles. The left and right columns show phenotypes of individuals injected with dsRNA of malE and DII, respectively. (A, B) First thoracic limb (T1). The exopodite and endopodite were shortened by DII-dsRNA. (C, D) Third and fourth thoracic limbs (T3/4), having the same morphology. The exopodite was shrunk in DII-dsRNA-injected juveniles. (E, F) Fifth thoracic limb (T5). The exopodite was shortened and twisted by DII-dsRNA. $(G, H)$ Lateral view of the rostrum and head. An arrowhead indicates an ocellus. $(\mathrm{I}, \mathrm{J})$ Lateral view of abdomens. An arrow and arrowhead show an abdominal claw and abdominal setae. Ep, epipodite; En, endopodite; Ex, exopodite; $F c$, filter comb. Scale bars $=100 \mu \mathrm{m}$.

Additional file 4: Primer sequences for in situ hybridization, dsRNA and Q-PCR.

Competing interests

The authors declare that they have no competing interests.

\section{Authors' contributions}

All authors designed the experiments; $\mathrm{CH}, \mathrm{KT}$ and $\mathrm{HM}$ performed and analyzed the experiments; $\mathrm{CH}$, JS and TI wrote the paper. KT, HM, YO, NT and SM discussed and commented on results and edited the manuscript. All authors have read and approved the final manuscript.

\section{Acknowledgements}

The authors are grateful to Dr. Raphael Guzman, Department of Molecular Cell Biology and Cancer Research Laboratory of University of California, Berkeley, for his critical reading of this manuscript. Daphnia pulex genomic sequence data was produced by The Center for Genomics and Bioinformatics at Indiana University and distributed via wFleaBase in collaboration with the Daphnia Genomics Consortium https://wiki.cgb. indiana.edu/display/DGC/Home. We thank members of the lguchi laboratory for helpful advice and discussions. This work was supported by a JSPS Research Fellowship for Young Scientists to CH (No.12J04065), KT (No.12J05579), a grant from Ministry of the Environment, Japan and MEXT KAKENHI Grant Number 24657022, 24370029 to TI, and a grant from the National Institute of Environmental Health Sciences to JRS (NIEHS R01 ES019324). Our work benefits from, and contributes to the Daphnia Genomics Consortium.

\section{Author details}

'Okazaki Institute for Integrative Bioscience, National Institute for Basic Biology, National Institutes of Natural Sciences, 5-1 Higashiyama, Myodaiji, Okazaki, Aichi 444-8787, Japan. ${ }^{2}$ Department of Basic Biology, Faculty of Life Science, Graduate University for Advanced Studies (SOKENDAI), 5-1 Higashiyama, Myodaiji, Okazaki, Aichi 444-8787, Japan. ${ }^{3}$ Environmental Quality Measurement Section, Research Center for Environmental Risk, National Institute for Environmental Studies, 16-2 Onogawa, Tsukuba, Ibaraki 305-8506, Japan. ${ }^{4}$ School of Public and Environmental Affairs, Indiana University, 1315 East Tenth Street, Bloomington IN 47405, USA.

Received: 19 September 2013 Accepted: 31 October 2013 Published: 5 November 2013

\section{References}

1. Beller M, Oliver B: One hundred years of high-throughput Drosphila research. Chromosome Res 2006, 14:349-362.

2. Pena-Castillo L, Hughes TR: Why are there still over 1000 uncharacterized yeast genes? Genetics 2007, 176:7-14

3. Colbourne JK, Pfrender ME, Gilbert D, Thomas WK, Tucker A, Oakley TH, Tokishita S, Aerts A, Arnold GJ, Basu MK, Bauer DJ, Cáceres CE, Carmel L, Casola C, Choi J-H, Detter JC, Dong Q, Dusheyko S, Eads BD, Fröhlich T, Geiler-Samerotte KA, Gerlach D, Hatcher P, Jogdeo S, Krijgsveld J, Kriventseva EV, Kültz D, Laforsch C, Lindquist E, Lopez J, et al: The ecoresponsive genome of Daphnia pulex. Science 2011, 331:555-561.

4. Bernstein E, Denli AM, Hannon GJ: The rest is silence. RNA 2001, 7:1509-1521.

5. Zamore PD: RNA interference: listening to the sound of silence. Nat Struct Biol 2001, 8:746-750.

6. Fire A, Xu S, Montgomery MK, Kostas SA, Driver SE, Mello CC: Potent and specific genetic interference by doublestranded RNA in Caenorhabditis elegans. Nature 1998, 391:806-811.

7. Wargelius A, Ellingsen S, Fjose A: Double-stranded RNA induces specific developmental defects in zebrafish embryos. Biochem Biophys Res Commun 1999, 263:156-161. 
8. Alvarado AS, Newmark PA: Double-stranded RNA specifically disrupts gene expression during planarian regeneration. Proc Natl Acad Sci USA 1999, 96:5049-5054.

9. Lohmann JU, Endl I, Bosch TC: Silencing of developmental genes in Hydra. Dev Biol 1999, 214:211-214.

10. Cogoni C, Macino G: Homology-dependent gene silencing in plants and fungi: a number of variations on the same theme. Curr Opin Microbiol 1999, 2:657-662.

11. Misquitta L, Paterson BM: Targeted disruption of gene function in Drosophila by RNA interference: a role for nautilus in embryonic somatic muscle formation. Proc Natl Acad Sci USA 1999, 96:1451-1456.

12. Wianny F, Zernicka-Goetz M: Specific interference with gene function by double-stranded RNA in early mouse development. Nat Cell Biol 2000, 2:70-75.

13. Kato $Y$, Shiga $Y$, Kobayashi K, Tokishita S, Yamagata H, Iguchi T, Watanabe H: Development of an RNA interference method in the cladoceran crustacean Daphnia magna. Dev Genes Evol 2011, 220:337-345.

14. Miyakawa H, Toyota K, Hirakawa I, Ogino Y, Miyagawa S, Oda S, Tatarazako $\mathrm{N}$, Miura T, Colbourne JK, lguchi T: A mutation in the receptor Methoprene-tolerant alters juvenile hormone response in insects and crustaceans. Nat Commun 1856, 2013:4.

15. Kato $Y$, Kobayashi $K$, Watanabe $H$, Iguchi T: Environmental sex determination in the branchiopod crustacean Daphnia magna: deep conservation of a Doublesex gene in the sex-determining pathway. PLoS Genet 2011, 7:e1001345.

16. Kato Y, Matsuura T, Watanabe H: Genomic integration and germline transmission of plasmid injected into crustacean Daphnia magna eggs. PLOS ONE 2012, 7:e45318.

17. Panganiban G, Rubenstein JLR: Developmental functions of the Distal-less/ Dlx homeobox genes. Development 2002, 129:4371-4386.

18. Cohen SM, Bronner G, Kuttner F, Jurgens G, Jackle H: Distal-less encodes a homeodomain protein required for limb development in Drosophila. Nature 1989, 338:432-434.

19. Beermann A, Jay DG, Beeman RW, Hulskamp M, Tautz D, Jurgens G: The Short antennae gene of Tribolium is required for limb development and encodes the orthologue of the Drosophila Distal-less protein. Development 2001, 128:287-297.

20. Yoshiyama N, Tojo K, Hatakeyama M: A survey of the effectiveness of non-cell autonomous RNAi throughout development in the sawfly, Athalia rosae (Hymenoptera). J Insect Physiol 2013, 59:400-407.

21. Liubicich DM, Serano JM, Pavlopoulos A, Kontarakis Z, Protas ME, Kwan E, Chatterjee S, Tran KD, Averof M, Patel NH: Knockdown of Parhyale Ultrabithorax recapitulates evolutionary changes in crustacean appendage morphology. Proc Natl Acad Sci USA 2009, 106:13892-13896.

22. Schoppmeier M, Damen WG: Double-stranded RNA interference in the spider Cupiennius salei: the role of Distal-less is evolutionarily conserved in arthropod appendage formation. Dev Genes Evol 2001, 211:76-82.

23. Khila A, Grbić M: Gene silencing in the spider mite Tetranychus urticae: dsRNA and siRNA parental silencing of the Distal-less gene. Dev Genes Evol 2007, 217:241-251.

24. Zaffagnini F: Reproduction in Daphnia. Mem Inst Ital Idrobiol 1987, 45:245-284

25. Hiruta C, Nishida C, Tochinai S: Abortive meiosis in the oogenesis of parthenogenetic Daphnia pulex. Chromosome Res 2010, 18:833-840.

26. Cohen SM, Jurgens G: Proximal-distal pattern formation in Drosophila: cell autonomous requirement for Distal-less gene activity in limb development. EMBO J 1989, 8:2045-2055.

27. Shiga $Y$, Yasumoto R, Yamagata H, Hayashi S: Evolving role of Antennapedia protein in arthropod limb patterning. Development 2002, 129:3555-3561.
28. Elendt BP, Bias WR: Trace nutrient deficiency in Daphnia magna cultured in standard medium for toxicity testing: effects of the optimization of culture conditions on life history parameters of $D$. magna. Water Res 1990, 24:1157-1167.

29. Spanier Kl, Leese F, Mayer C, Colbourne JK, Gilbert D, Pfrender ME, Tollrian R: Predator-induced defences in Daphnia pulex: Selection and evaluation of internal reference genes for gene expression studies with real-time PCR. BMC Mol Biol 2010, 11:50.

doi:10.1186/1472-6750-13-96

Cite this article as: Hiruta et al:: Development of a microinjection system for RNA interference in the water flea Daphnia pulex. BMC Biotechnology 2013 13:96.

\section{Submit your next manuscript to BioMed Central and take full advantage of:}

- Convenient online submission

- Thorough peer review

- No space constraints or color figure charges

- Immediate publication on acceptance

- Inclusion in PubMed, CAS, Scopus and Google Scholar

- Research which is freely available for redistribution

Submit your manuscript at www.biomedcentral.com/submit
C Biomed Central 